\title{
Pain Science Education for Children Living With and Beyond Cancer: Challenges and Research Agenda
}

\author{
Emma Rheel ${ }^{1}$, Lauren Heathcote ${ }^{2}$, Jutte Van der Werff-ten Bosch ${ }^{3}$, Fiona Schulte ${ }^{4}$, and \\ Joshua Pate ${ }^{5}$ \\ ${ }^{1}$ Vrije Universiteit Brussel \\ ${ }^{2}$ King's College London Institute of Psychiatry Psychology and Neuroscience \\ ${ }^{3}$ University Hospital Brussels \\ ${ }^{4}$ University of Calgary Cumming School of Medicine \\ ${ }^{5}$ University of Technology Sydney
}

February 2, 2022

\begin{abstract}
Pain in children living with and beyond cancer is understudied and undertreated. Pain science education (PSE) is a conceptual change strategy facilitating patients' understanding of the biopsychosocial aspects of pain. Preliminary studies on the adaptation of PSE interventions to adults with and beyond cancer provide a foundation for pediatric research. PSE could help childhood cancer survivors experiencing persistent pain and pain-related worry after active treatment. PSE may also help children receiving cancer treatment, providing them with a foundation of adaptive pain beliefs and cognitions, and preparing them for procedural and treatment-related pain. We direct this paper towards pediatric oncology clinicians, policy makers and researchers working with children living with and beyond cancer. We aim to; (1) identify challenges in adapting PSE for children living with and beyond cancer, (2) offer possible solutions, and (3) propose research questions to guide the implementation of PSE for children living with and beyond cancer.
\end{abstract}

\section{Hosted file}

Manuscript.docx available at https://authorea.com/users/458575/articles/555090-pain-scienceeducation-for-children-living-with-and-beyond-cancer-challenges-and-research-agenda

\section{Hosted file}

Table 1.docx available at https://authorea.com/users/458575/articles/555090-pain-scienceeducation-for-children-living-with-and-beyond-cancer-challenges-and-research-agenda 